Ekstrak Daun Pandan (Pandanus amaryllifous Roxb)... (Victor Kayadoe, dkk)

\title{
EKSTRAK DAUN PANDAN (Pandanus amaryllifous Roxb) SEBAGAI INHIBITOR KOROSI BAJA SS-304 DALAM LARUTAN $\mathrm{H}_{2} \mathrm{SO}_{4}$
}

\author{
THE EXTRACT OF PANDAN LEAF (Pandanus amaryllifous Roxb) \\ AS CORROSION INHIBITORS OF SS-304 IN $\mathrm{H}_{2} \mathrm{SO}_{4}$ SOLUTION
}

\author{
Victor Kayadoe', Muhamad Fadli, Rahman Hasim, Mitra Tomasoa \\ Program Studi Pendidikan Kimia \\ Fakultas Keguruan dan Ilmu Pendidikan Universitas Pattimura \\ J1. Ir. M. Putuhena, Kampus Poka-Ambon, 97233 \\ email: ${ }^{1}$ veky_kayadoe@yahoo.com
}

\begin{abstract}
ABSTRAK
Penelitian ini bertujuan untuk mengetahui efisiensi inhibisi dan laju korosi baja SS-304 dalam larutan $\mathrm{H}_{2} \mathrm{SO}_{4}$ menggunakan ekstrak daun pandan (Pandanus amaryllifous Roxb) dengan metode gravimetri. Ekstrak daun pandan diperoleh melalui ekstraksi maserasi menggunakan etanol. Hasil uji fitokimia ekstrak daun pandan menunjukkan adanya kandungan senyawa-senyawa metabolit sekunder flavonoid, steroid, alkaloid, antrakuinon, dan tanin. Pada uji inhibisi korosi, dilakukan variasi konsentrasi ekstrak daun pandan dan suhu untuk mengetahui pengaruhnya terhadap efisiensi inhibisi korosi baja SS-304 dalam larutan $\mathrm{H}_{2} \mathrm{SO}_{4} 1 \mathrm{M}$ selama 3 jam. Hasil penelitian menunjukkan bahwa efisiensi inhibisi meningkat dengan peningkatan konsentrasi inhibitor, yang berarti semakin menurunnya laju korosi. Efisiensi inhibisi optimum diperoleh pada konsentrasi inhibitor 0,8\%, yakni $89,06 \%$ dengan laju korosi 5,15 mm/tahun. Sebaliknya, meningkatnya suhu mengakibatkan menurunnya efisiensi inhibisi, yang berarti meningkatnya laju korosi. Efisiensi terrendah diperoleh pada suhu $50{ }^{\circ} \mathrm{C}$, yakni $11,56 \%$ dengan laju korosi $74,33 \mathrm{~mm} /$ tahun.
\end{abstract}

Kata Kunci: Baja SS-304, Ekstrak daun pandan, Inhibitor korosi, Media HCl.

\begin{abstract}
This study aims to determine the efficiency of inhibition and corrosion rate of SS-304 in $\mathrm{H}_{2} \mathrm{SO}_{4}$ solution using the extract of pandan leaf (Pandanus amaryllifous Roxb) by gravimetric method. The extract of pandan leaf was obtained by maceration extraction using ethanol. Based on phytochemical test, it is found that there are several compounds of secondary metabolites of flavonoids, steroids, alkaloids, anthraquinonoid, and tannins in the exract of pandan leaf. In the corrosion inhibition test, it was performed various concentration toward the extract of pandan leaf and temperature to determine its effect on corrosion inhibition efficiency of SS-304 in $\mathrm{H}_{2} \mathrm{SO}_{4} 1 \mathrm{M}$ solution for 3 hours. The results showed that the inhibition efficiency significantly increases with the increasing of inhibitor concentration, which means the reduction in the corrosion rate. The optimum inhibition efficiency was obtained at inhibitor concentration of $0.8 \%$, which was $89.06 \%$ with a corrosion rate of $5.15 \mathrm{~mm} /$ year. Conversely, the increasing of temperatures caused the reduction of inhibition efficiency, which means the increasing of corrosion rate. The lowest efficiency was obtained at a temperature of $50{ }^{\circ} \mathrm{C}$, which was $11.56 \%$ with corrosion rate of $74.33 \% \mathrm{~mm} /$ year
\end{abstract}

Keywords: corrosion inhibitors, $\mathrm{H}_{2} \mathrm{SO}_{4}$ solution, $\mathrm{SS}-304$, the extract of pandan leaf. 


\section{PENDAHULUAN}

Baja merupakan salah satu jenis logam paduan yang banyak digunakan dalam perindustrian. Salah satunya adalah baja tahan karat (Stainless Steel) 304 atau yang sering dikenal dengan SS-304. Fenomena yang tidak dapat dipungkiri keberlangsungannya pada suatu logam yang digunakan dalam industri adalah korosi atau pengkaratan, yang mengakibatkan penurunan daya guna logam tersebut.

Banyak proses dalam industri yang dapat mengakibatkan korosi baja SS-304, di antaranya proses pickling, cleaning, descaling, maupun pengasaman minyak. Keseluruhan proses ini berlangsung dalam media asam yang melibatkan penggunaan asam-asam mineral, seperti asam klorida dan asam sulfat (Bentiss, dkk., 2000). Walaupun baja memiliki beberapa kelebihan, yaitu relatif kuat, keras, mengkilap, mudah dibersihkan, dan tahan terhadap kondisi dingin maupun panas, namun asam-asam mineral dengan kereaktifan yang cukup tinggi dapat menyebabkan terjadinya korosi pada baja tersebut. Oleh karena itu dibutuhkan suatu pencegahan untuk menghindari kerugian yang dapat ditimbulkan akibat korosi. Salah satu caranya dengan menambahkan inhibitor korosi (Scendo, 2007).

Inhibitor korosi berdasarkan sumbernya dibedakan atas inhibitor organik dan anorganik. Pemilihan suatu inhibitor tidak hanya didasarkan pada kemampuannya dalam menghambat korosi dengan efisiensi yang tinggi, namun aspek tingkat toksisitas terutama bila diaplikasikan dalam industri makanan dan juga masalah pencemaran lingkungan perlu dipertimbangkan. Alasan inilah yang membatasi penggunaan inhibitor dari bahan anorganik. Pertimbangan terhadap harga yang mahal dan tingkat toksisitas yang tinggi dari bahan kimia sintetik, mendorong dikembangkannya sumber alternatif inhibitor organik yang murah dan ramah lingkungan dari ekstrak bahan alam.

Pada penelitian ini, dimanfaatkan ekstrak daun pandan sebagai alternatif inhibitor korosi baja SS-304 dalam media $\mathrm{H}_{2} \mathrm{SO}_{4}$. Hasil uji fitokimia terhadap kandungan senyawa kimia dalam daun pandan telah dilaporkan Prameswari dan Widjanarko (2014) bahwa ekstrak air, etanol dan air:etanol dari daun pandan wangi positif mengandung alkaloid, tannin, flavonoid, dan polifenol. Kadar flavonoid total dan fenolik total dalam ekstrak daun pandan yang maksimum diperoleh pada ekstrak etanol 96\%, masing-masing sebesar 478,7629 dan 99,4086 $\mathrm{mg} / \mathrm{g}$ (Agustiningsih, dkk., 2010).

Senyawa-senyawa organik yang terkandung dalam ekstrak daun pandan tersebut dapat berperan sebagai inhibitor korosi karena memenuhi karakteristik inhibitor senyawa organik seperti adanya heteroatom, gugus polar, ikatan $\pi$, serta pasangan elektron bebas yang menjadi sarana bagi inhibitor berikatan dengan logam secara koordinasi (Spinelli, dkk., 2009). Beberapa penelitian telah melaporkan penggunaan ekstrak bahan alam yang mengandung senyawa-senyawa organik ini dapat menghambat korosi logam dengan efisiensi yang cukup tinggi. Ekstrak daun pepaya yang mengandung alkaloid, saponin, flavonoid, dan tannin dilaporkan memiliki efisiensi inhibisi korosi baja St.37 sebesar 96,22\% dalam media asam sulfat (Irianty dan Khairat, dkk., 2013), ekstrak daun sirsak (Annona Muricata $L$.) yang mengandung flavonoid, saponin, terpen, alkaloid dan tannin di laporkan memiliki efisiensi inhibisi korosi baja ringan sebesar $80,61 \%$ dalam media HCl 1 N (Vimala, dkk., 2012), dan ekstrak kayu akasia yang mengandung tannin dilaporkan dapat menurunkan laju korosi baja lunak dalam media $\mathrm{H}_{2} \mathrm{SO}_{4} \quad 0,5 \mathrm{M}$ selama 3 hari sebesar $0,0089 \mathrm{mg} / \mathrm{m}^{2}$.jam dibandingkan tanpa inhibitor sebesar 1,013503 mg/m².jam (Gusti, dkk., 2013). 
Berdasarkan latar belakang yang telah dikemukakan, kemampuan ekstrak daun pandan dalam menghambat proses korosi perlu diuji. Pada penelitian ini, uji inhibisi korosi dilakukan terhadap baja SS304 dalam media $\mathrm{H}_{2} \mathrm{SO}_{4}$ menggunakan metode gravimetri, dengan variasi konsentrasi ekstrak dan suhu inhibisi untuk mengetahui pengaruhnya terhadap efisiensi inhibisi dan laju korosi.

\section{METODE PENELITIAN}

\section{Alat dan Bahan}

Peralatan yang digunakan dalam penelitian ini adalah gelas kimia, gelas ukur, labu takar, botol sampel, hot plate, stop watch, benang nilon, shaker, neraca analitik, dan rotary vacuum evaporator.

Bahan yang digunakan dalam penelitian ini adalah Lempeng baja SS-304 diperoleh dari UD. Banyu Mas SurabayaJawa Timur, daun pandan dari desa PokaAmbon, etanol, $\mathrm{H}_{2} \mathrm{SO}_{4}$ (96\%), aseton, akuades, pelat KLT, pereaksi uji fitokimia.

\section{Prosedur Kerja}

\section{Preparasi spesimen baja SS-304}

Lempeng baja SS-304 dipotong

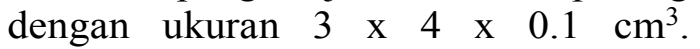
Sebelum digunakan, baja terlebih dahulu digosok menggunakan kertas ampelas, dicuci dengan akuades dan aseton, dibilas lagi dengan akuades kemudian dikeringkan.

\section{Pembuatan ekstrak daun pandan}

Ditimbang $50 \mathrm{~g}$ serbuk kering daun pandan dimasukkan kedalam botol kaca, kemudian ditambahkan $375 \mathrm{~mL}$ etanol 96\%. Campuran dibiarkan selama 5 hari sambil diaduk 3-4 jam perhari dengan shaker, kemudian disaring. filtrat yang dihasilkan diuapkan pelarutnya menggunakan hingga diperoleh ekstrak pekat $(100 \%)$, yang selanjutnya dilakukan uji fitokimia untuk mengetahui kandungan senyawa (Harbone, 1987; Adfa, 2005, Vimala, dkk., 2012).

\section{Uji Fitokimia}

\section{Uji senyawa alkaloid}

Larutan ekstrak daun pandan ditotolkan pada 4 lempeng lapis tipis silika gel 60 F254 berukuran 2x8 cm dan dielusi menggunakan eluen heksan:kloroform (2:8), hasil optimasi. Tiap noda yang diperoleh setelah dielusi kemudian disemprot dengan pereaksi Dragendorff dan dilanjutkan dengan $\mathrm{H}_{2} \mathrm{SO}_{4} \quad 5 \%$ etanolik, adanya alkaloid ditunjukkan dengan diperoleh noda cokelat pada kromatogram.

\section{Uji Senyawa Fenolik}

Sebanyak $2 \mathrm{~mL}$ ekstrak daun pandan dilarutkan dengan $2 \mathrm{~mL} \mathrm{FeCl}_{3} 1 \%$, adanya fenolik menimbulkan warna hijau, merah ungu, biru atau hitam kuat.

\section{Uji Senyawa Steroid}

Pengujian steroid dilakukan dengan cara disemprotkan kromatogram hasil KLT dengan pereaksi Liebermann-Burchard dan dilanjutkan dengan pemanasan di oven pada suhu $100{ }^{\circ} \mathrm{C}$ selama 10 menit, adanya steroid ditunjukan dengan perolehan noda berwarna hijau-biru pada kromatogram.

\section{Uji Senyawa Antrakuinon}

Pengujian antrakuinon dilakukan dengan cara disemprotkan kromatogram hasil KLT dengan $\mathrm{KOH} \quad 5 \%$ adanya antrakoinon ditunjukkan dengan diperoleh noda berwarna merah pada kromatogram

\section{Uji Senyawa Flavonoid}

Sebanyak $2 \mathrm{~mL}$ Ekstrak daun pandan dilarutkan dalam $2 \mathrm{~mL} \mathrm{HCl} 2 \mathrm{~N}$ dan ditambahkan serbuk Zn, adanya flavonoid ditunjukan melalui perubahan warna orange ketika dikocok.

\section{Uji Senyawa Terpenoid}

Sebanyak $2 \mathrm{~mL}$ kloroform ditambahkan ke 0,5 g ekstrak, $\mathrm{H}_{2} \mathrm{SO}_{4}$ pekat (3 $\mathrm{mL}$ ) secara hati-hati ditambahkan hingga membentuk lapisan. Munculnya 
warna cokelat kemerahan menunjukan adanya terpenoid.

\section{Uji Senyawa Tanin}

Sebanyak 0,5 g ektrak dididihkan dengan $10 \mathrm{~mL}$ air dalam tabung reaksi, kemudian disaring. Sedikit tetes $\mathrm{FeCl}_{3}$ $0,1 \%$ ditambahkan dan teramati warna hijau kecoklatan atau warna hitam biru.

\section{Preparasi Media Korosi}

Larutan $\mathrm{H}_{2} \mathrm{SO}_{4} \quad 1 \quad \mathrm{M}$ diperoleh dengan cara melarutkan $\mathrm{H}_{2} \mathrm{SO}_{4}$ pekat (96\%) sebanyak 55,52 $\mathrm{mL}$ dengan akuades dalam labu takar $1 \mathrm{~L}$. Untuk pembuatan media korosi dengan penambahan ekstrak daun pandan $10 \%, 10 \mathrm{~mL}$ ekstrak daun pandan $100 \%$ dimasukan ke dalam labu takar $100 \mathrm{~mL}$ kemudian ditambahkan $\mathrm{H}_{2} \mathrm{SO}_{4} 1 \mathrm{M}$ hingga tanda batas. Perlakuan yang sama dilakukan pada ekstrak daun pandan $7,5,5$, dan 2,5\% dengan penambahan ekstrak daun pandan $100 \%$ masing-masing $7,5,5$, dan 2,5 mL.

\section{Pengujian Efisiensi Inhibisi}

Uji efisisensi inhibisi dilakukan dengan metode gravimetri. Spesimen ditimbang dengan neraca analitis kemudian direndam dalam media korosi tanpa inhibitor dan media korosi dengan inhibitor selama 3 jam pada konsentrasi ekstrak daun 10, 7,5, 5, dan 2,5\%. Konsentrasi dengan efisiensi inhibisi yang optimum digunakan untuk variasi suhu, yaitu pada suhu 30,40,45, dan $50{ }^{\circ} \mathrm{C}$. Pengujian efisiensi inhibisi, baik pada variasi konsentrasi inhibitor maupun variasi suhu dilakukan secara triplo.

Efisiensi inhibisi dihitung menggunakan rumus:

$\%$ Efisiensi Inhibisi $=\frac{\mathrm{W}_{\mathrm{o}}-\mathrm{W}_{\mathrm{i}}}{\mathrm{W}_{\mathrm{o}}} \times 100 \%$

Dengan Wo adalah pengurangan massa spesimen pada media korosi tanpa inhibitor, dan Wi adalah pengurangan massa spesimen pada media korosi dengan inhibitor.
Laju korosi per tahun dihitung menggunakan rumus berdasarkan standar ASTM (Soltani, Tavakkoli, Khayatkashani, Jalali, \& Mosavizade, 2012) (Soltani, dkk., 2012):

$$
\text { Laju korosi (mm/tahun) }=\frac{\mathrm{K} \times \mathrm{W}}{\mathrm{A} \times \mathrm{T} \times \mathrm{D}}
$$

Dengan :

$\mathrm{K}=$ Konstanta laju korosi (87600)

$\mathrm{W}=$ Pengurangan berat $(\mathrm{g})$

$\mathrm{A}=$ Luas permukaan logam $\left(\mathrm{cm}^{2}\right)$

$\mathrm{T}=$ Waktu ekspos (jam)

$\mathrm{D}=$ densitas logam $\left(\mathrm{g} / \mathrm{cm}^{3}\right)$

\section{HASIL DAN PEMBAHASAN}

\section{Ekstraksi Daun Pandan}

Ekstrak daun pandan diperoleh dengan metode ekstraksi maserasi serbuk kering daun pala dalam pelarut etanol. Daun pandan dibuat menjadi serbuk agar proses ekstraksi optimal. Proses maserasi dilakukan pada suhu ruang agar tidak merusak senyawa dalam ektrak tersebut selama 1x24 jam. Selama ekstraksi, pengadukan dilakukan menggunakan shaker dengan kecepatan $100 \mathrm{rpm}$ agar kontak antara pelarut dan sampel merata. Etanol yang bersifat polar akan melarutkan senyawa-senyawa yang bersifat polar dalam ekstrak serbuk daun pandan, berdasarkan prinsip "like dissolve like" (Khopkar, 2003). Pelarut etanol dalam ekstraksi serbuk daun pandan wangi telah dilaporkan Agustiningsih, dkk. (2010) sebagai pelarut yang paling maksimal mengekstrak senyawa fenolik dan flavonoid.

Maserat yang diperoleh disaring dan filtratnya dievaporasi menggunakan rotary vacuum evaporator untuk menguapkan pelarut, sehingga ekstrak tidak rusak oleh suhu tinggi (Damayanti dan Fitriana, 2012). Ekstrak yang telah bebas pelarut ditunjukkan pada Gambar 1. 


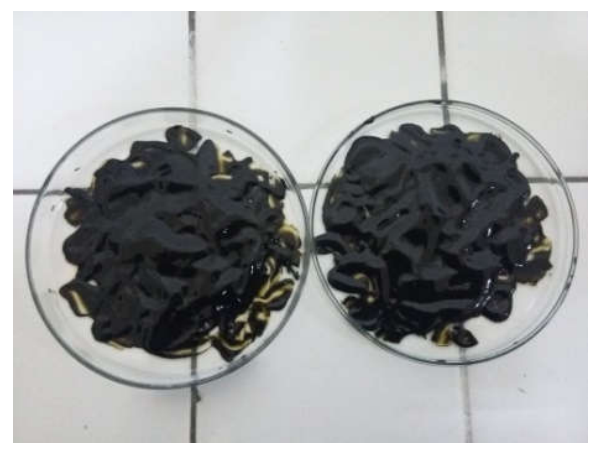

Gambar 1. Ekstrak Daun Pandan

\section{Hasil Uji Fitokimia}

Analisis fitokimia ekstrak etanol daun pandan menggunakan berbagai pereaksi kimia bertujuan untuk mengetahui adanya kandungan senyawa metabolik sekunder dalam ekstrak, yang berperan dalam proses inhibisi (Irianty dan Khairat, 2013; Vimala, dkk., 2012; Gusti, dkk., 2013). Uji fitokimia terhadap kandungan beberapa golongan senyawa dengan pereaksi semprot diawali dengankan optimasi rasio pelarut dari pelarut nonpolar (nheksana), semipolar (etil asetat), hingga pelarut polar (etanol). Berdasarkan hasil penelitian, rasio pelarut dengan pemisahan yang paling baik dengan spot-spot yang paling jelas diperoleh pada rasio pelarut $n$-heksana:kloroform $=1: 8$.
Hasil optimasi ini kemudian dijadikan acuan untuk mengidentifikasi senyawa-senyawa yang terkandung dalam ekstrak daun pandan. Sementara senyawa lainnya digunakan pereaksi tertentu dengan cara menambahkan ke dalam larutan ekstrak dalam tabung reaksi. Hasil uji fitokimia ekstrak daun pandan ditunjukkan pada Gambar 2 dan Tabel 1.

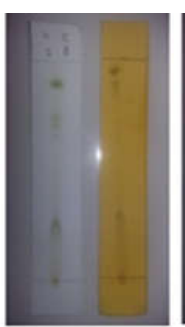

(a)

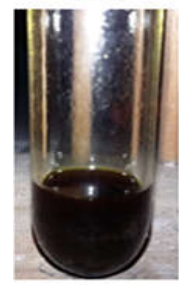

(e)

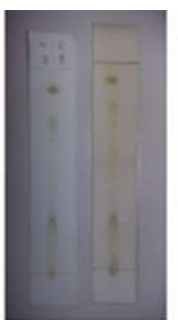

(b)

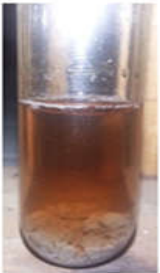

(f)

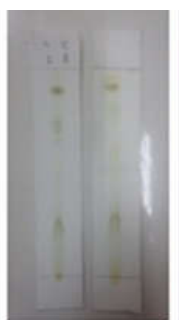

(c)

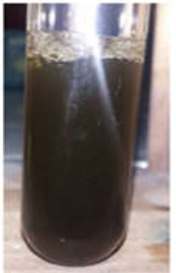

(g)

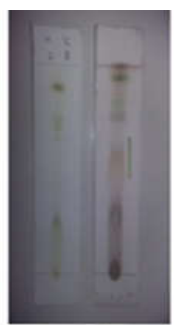

(d)

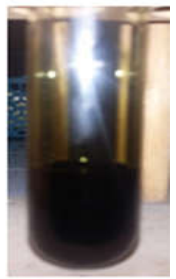

(h)
Gambar 2. Hasil Uji Fitokimia: Alkaloid (a), antrakuinon (b), Polifenol (c) dan Steroid (d), Ekstrak Daun Pandan (kontrol) (e), flavonoid (f), tannin (g), terpenoid (h)

Tabel 1. Hasil Uji Fitokimia Ekstrak Daun Pandan

\begin{tabular}{|c|c|c|c|}
\hline $\begin{array}{c}\text { Golongan } \\
\text { Senyawa } \\
\text { Metabolit } \\
\text { Sekunder } \\
\end{array}$ & Jenis Pereaksi & Perubahan & Hasil \\
\hline Alkaloid & Dragendorff & $\begin{array}{l}\text { Noda cokelat atau orange nampak } \\
\text { pada sinar tampak }\end{array}$ & + \\
\hline Flavonoid & Shinoda Test & Warna ekstrak menjadi orange & + \\
\hline Steroid & $\begin{array}{l}\text { Lieberman } \\
\text { Burchard }\end{array}$ & $\begin{array}{l}\text { Noda hijau atau biru pada sinar } \\
\text { tampak }\end{array}$ & + \\
\hline Antrakuinon & $\begin{array}{l}5 \% \mathrm{KOH} \\
\text { Alkaholis }\end{array}$ & $\begin{array}{l}\text { Intensitas noda berwarna kuning pada } \\
\text { sinar tampak semakin pekat }\end{array}$ & + \\
\hline Tanin & $\mathrm{FeCl}_{3} \quad 1 \%$ & Warna larutan hijau kecokelatan & + \\
\hline Terpenoid & Uji Salkowski & $\begin{array}{l}\text { Tidak terbentuk lapisan berwarna } \\
\text { cokelat kemerahan }\end{array}$ & - \\
\hline
\end{tabular}


Berdasarkan hasil uji fitokimia diperoleh bahwa ekstrak daun pandan mengandung senyawa-senyawa metabolit sekunder, seperti flavonoid, steroid, alkaloid, antrakuinon, polifenol dan tanin. Adanya kandungan senyawasenyawa ini mengindikasikan bahwa ekstrak daun pandan berpotensi dalam menghambat laju korosi baja SS-304 dalam larutan $\mathrm{H}_{2} \mathrm{SO}_{4}$ karena adanya heteroatom, gugus polar, ikatan $\pi$ dan pasangan elektron bebas.

\section{Pengaruh Konsentrasi Ekstrak Daun Pandan terhadap Inhibisi Korosi Baja SS-304}

Untuk mempelajari pengaruh konsentrasi arginin, variabel lain dibuat konstan yakni suhu ruang, waktu perendaman 3 jam dan konsentrasi media asam $1 \mathrm{M}$. Hasil pengujian pengaruh konsentrasi arginin terhadap efisiensi inhibisi dan laju korosi per tahun baja SS304 dalam media $\mathrm{H}_{2} \mathrm{SO}_{4}$ ditunjukkan pada Tabel 2.

Tabel 2. Pengaruh Konsentrasi ekstrak daun pandan terhadap Efisiensi Inhibisi dan Laju Korosi Per Tahun

\begin{tabular}{cccccc}
\hline $\begin{array}{c}\text { Konse- trasi } \\
\text { ekstrak } \\
\text { daun }\end{array}$ & $\begin{array}{c}\text { Luas Baja } \\
\left.\mathbf{( c m}^{2}\right)\end{array}$ & $\begin{array}{c}\text { Berat } \\
\text { Awal (g) }\end{array}$ & $\begin{array}{c}\text { Berat } \\
\text { Akhir (g) }\end{array}$ & EI (\%) & $\begin{array}{c}\text { Laju Korosi Per } \\
\text { tahun (mm/tahun) }\end{array}$ \\
\hline 0 & 23,68 & 6,582 & 6,280 & - & 46,44 \\
0,5 & 23,62 & 6,053 & 5,935 & 60,94 & 18,19 \\
0,6 & 24,66 & 6,204 & 6,114 & 70,31 & 13,24 \\
0,7 & 23,41 & 6,341 & 6,289 & 82,81 & 8,07 \\
0,8 & 23,31 & 6,053 & 6,020 & 89,90 & 5,15 \\
\hline
\end{tabular}

Berdasarkan Tabel 2, semakin besar konsentrasi inhibitor yang ditambahkan, efisiensi inhibisinya (\%EI) semakin besar dan laju korosi baja SS-304 semakin menurun. Hal ini disebabkan, tingginya konsentrasi ekstrak daun pandan mengakibatkan frekuensi interaksi antara sisi aktif dari molekul dengan permukaan baja semakin banyak, sehingga membentuk lapisan pasif (passive layer) yang stabil. Oleh karena itu semakin besar area permukaan baja yang tertutupi dan menghalangi serangan larutan korosif (Soltani, dkk., 2012; Amin \& Ibrahim, 2011). Pada penelitian ini diperoleh efisiensi optmimum pada konsentrasi inhibitor $0,8 \%$ sebesar $89 \%$.

Keberadaan ion $\mathrm{H}^{+}$dalam media korosi $\left(\mathrm{H}_{2} \mathrm{SO}_{4}\right)$ mengakibatkan zat tersebut bersifat agresif terhadap pelarutan logam. Pengamatan saat pengujian inhibisi menunjukkan gas hidrogen yang dihasilkan saat perendaman baja dalam media $\mathrm{H}_{2} \mathrm{SO}_{4}$ tanpa inhibitor lebih banyak dibandingkan dalam media $\mathrm{H}_{2} \mathrm{SO}_{4}$ dengan penambahan inhibitor. Gas hidrogen yang teramati pada permukaan baja, menunjukkan proses korosi pada reaksi katodik akibat discharge ion hidrogen yang berasal dari larutan asam (Caliskan \& Akbas, 2011). Hubungan \%EI terhadap konsntrasi ekstrak daun pandan ditunjukkan pada Gambar 3.

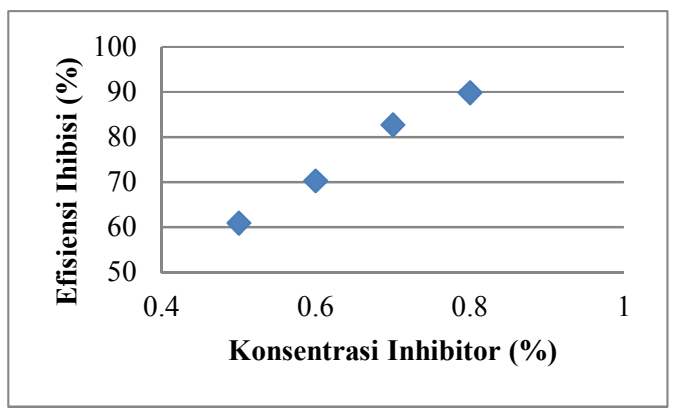

Gambar 3. Hubungan \%EI terhadap Konsentrasi Ekstrak Daun Pandan

Peningkatan efisiensi inhibisi ini mengakibatkan menurunnya laju korosi per tahun (mm/tahun) dari 46,44 $\mathrm{mm} /$ tahun 
hingga $5,15 \mathrm{~mm} /$ tahun, yang berarti bahwa masa pemakaian baja SS-304 akan menjadi lebih dari delapan kali jika menggunakan inhibitor ekstrak daun pandan 0,8\% dibandingkan dengan tanpa inhibitor, sesuai Tabel 2 dan Gambar 4.

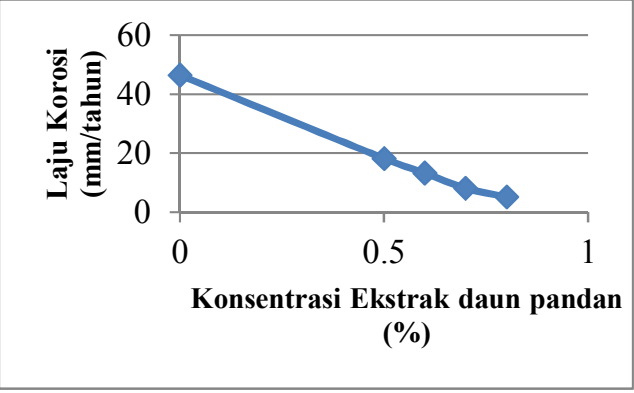

Gambar 4. Grafik Hubungan Laju Korosi terhadap Konsentrasi Ekstak Daun Pandan

Pengaruh suhu terhadap inhibisi korosi baja SS-304 menggunakan ekstrak daun Pandan

Berdasarkan hasil pengujian inhibisi dengan variasi konsentrasi ekstrak daun pandan, diperoleh efisiensi inhibisi yan optimum dalam media $\mathrm{H}_{2} \mathrm{SO}_{4} 1 \mathrm{M}$ pada kosentrasi ekstrak daun pandan 0,8\%. Konsentrasi ekstrak daun pandan yang menghasilkan efisiensi yang optimum ini selanjutnya digunakan untuk mempelajari pengaruh perubahan suhu terhadap efisien- si inhibisi ekstrak daun pandan terhadap korosi baja SS-304 dalam media $\mathrm{H}_{2} \mathrm{SO}_{4}$, dengan variabel lain dibuat tetap, yaitu waktu perendaman 3 jam dan kosentrasi $\mathrm{H}_{2} \mathrm{SO}_{4} 1$ M. Hasil uji inhibisi korosi dengan variasi suhu ditunjukkan pada Tabel 3.

Berdasarkan Tabel 3, dapat dilihat bahwa meningkatnya suhu menyebabkan bertambahnya kecepatan reaksi korosi. Hal ini terjadi karena makin tinggi suhu maka energi kinetika dari partikel-partikel yang bereaksi akan meningkat sehingga melampaui besarnya harga energi aktivasi dan akibatnya laju kecepatan reaksi (korosi) juga akan makin cepat, begitu juga sebaliknya. Menurut Shreir dkk (1994), Pada peningkatan suhu tertentu, laju difusi reaktan meningkat dua kali yang mengakibatkan proses aktivasi meningkat 10-100 kali.

Dengan adanya suhu tinggi, ionisasi larutan asam akan semakin cepat dan pori-pori permukaan logam akan semakin besar. Kondisi ini mengakibatkan difusi zat asam dan molekul oksigen pada pemukaan logam akan semakin cepat, sehingga pelarutan logam akan semakin cepat.

Tabel 3. Pengaruh Suhu Terhadap Efisiensi Inhibisi (\%) dan Laju Korosi per Tahun (mm/tahun) dalam Media $\mathrm{H}_{2} \mathrm{SO}_{4}$

\begin{tabular}{|c|c|c|c|c|c|c|c|}
\hline \multirow{2}{*}{$\begin{array}{l}\text { Suhu } \\
\left({ }^{\circ} \mathrm{C}\right)\end{array}$} & \multicolumn{2}{|c|}{$\begin{array}{c}\text { Luas Permukaan Baja } \\
\left(\mathrm{cm}^{2}\right)\end{array}$} & \multicolumn{2}{|c|}{ Selisih Berat Baja (g) } & \multicolumn{2}{|c|}{$\begin{array}{c}\text { Laju Korosi Per Tahun } \\
\text { (mm/tahun) }\end{array}$} & \multirow[t]{2}{*}{ EI(\%) } \\
\hline & $\begin{array}{c}\text { Tanpa } \\
\text { Inhibitor }\end{array}$ & $\begin{array}{l}\text { Dengan } \\
\text { Inhibitor }\end{array}$ & $\begin{array}{c}\text { Tanpa } \\
\text { Inhibitor }\end{array}$ & $\begin{array}{l}\text { Dengan } \\
\text { Inhibitor }\end{array}$ & $\begin{array}{c}\text { Tanpa } \\
\text { Inhibitor }\end{array}$ & $\begin{array}{l}\text { Dengan } \\
\text { Inhibitor }\end{array}$ & \\
\hline 27 & 23,68 & 23,31 & 0,3024 & 0,0330 & 46,44 & 5,37 & 89,06 \\
\hline 35 & 24,08 & 22,60 & 0,6095 & 0,0780 & 92,04 & 12,54 & 87,21 \\
\hline 40 & 25,40 & 24,94 & 0,9923 & 0,1205 & 142,06 & 17,57 & 87,86 \\
\hline 45 & 24,24 & 23,19 & 1,3372 & 0,1559 & 200,60 & 24,45 & 88,34 \\
\hline 50 & 23,49 & 24,27 & 1,9562 & 0,4961 & 302,83 & 74,33 & 74,64 \\
\hline
\end{tabular}




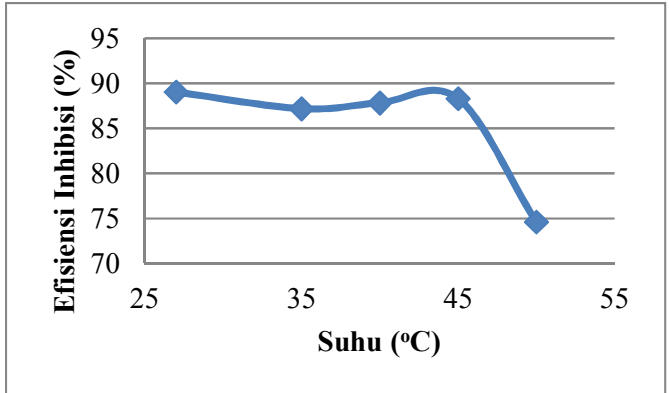

Gambar 5. Grafik Hubungan \%EI terhadap suhu

Grafik pada Gambar 5 menunjukkan pengaruh suhu yang tidak linear dengan efisiensi inhibisi. Hal ini menunjukkan kemampuan inhibisi ekstrak daun pandan pada korosi baja SS-304 pada suhu tinggi tidak stabil. Peningkatan suhu menyebabkan tingkat energi molekul pada permukaan logam mengalami pesaingan antara gaya adsorpsi dan gaya desorpsi dari logam (Wahyuningsih dkk, 2010). Secara keseluruhan peranan inhibitor dari ekstrak daun pandan dalam menghambat proses proses korosi baja dalam media $\mathrm{H}_{2} \mathrm{SO}_{4}$, namun seiring bertambahnya suhu, efisiensi inhibisi yang ditunjukan semakin berkurang. Penurunan efisiensi inhibisi, menunjukan bahwa peranan inhibitor dari eksrak daun pandan pada suhu yang tinggi relatif akan berkurang. Hal ini disebabkan karena adanya kompetisi difusi molekul inhibitor dengan zat korosif pada permukaan logam. Besarnya molekul yang terdapat dalam ekstrak daun pandan mengakibatkan difusinya lambat sehingga pada suhu tinggi, permukaan logam akan lebih dahulu diserang zat korosif. Pada suhu tinggi kekuatan adsorpsi dari molekul inhibitor menurun dan kekesatan atau kekasaran (roughening) permukaan logam akibat korosi yang mengakibatkan proses penghambatan menjadi berkurang.

Pengaruh suhu terhadap laju korosi per tahun (mm/tahun) baja SS-304 dalam media $\mathrm{H}_{2} \mathrm{SO}_{4}$ dengan dan tanpa inhibitor ekstrak daun pandan ditunjukkan pada Tabel 3. Berdasarkan Tabel 3 terlihat bahwa laju korosi tanpa inhibitor lebih tinggi dibandingkan tanpa inhibitor. Hal ini menunjukkan peranan Ekstrak daun pandan dalam menghambat korosi baja pada semua variasi suhu yang digunakan. Namun laju korosi baja, baik tanpa inhibitor maupun dengan inhibitor meningkat dengan naiknya suhu. Sebagaimana ditunjukkan pada grafik pada Gambar 6, laju korosi baja SS-304 meningkat sangat siginifikan pada suhu di atas $45^{\circ} \mathrm{C}$. Hal ini menunjukkan baja akan mengalami korosi dengan cepat pada suhu tinggi.

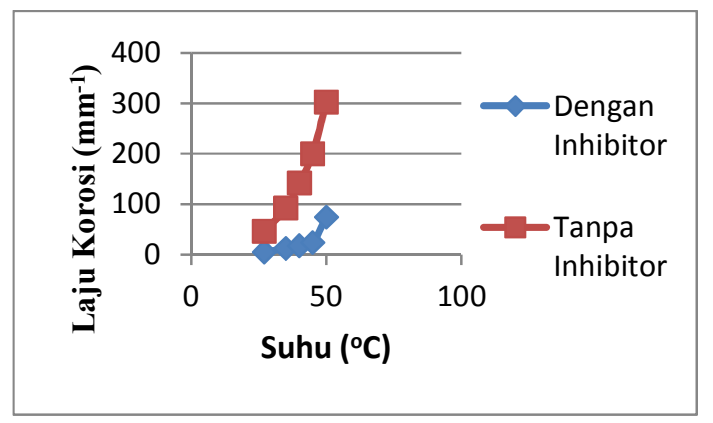

Gambar 6. Hubungan Laju Korosi (mm/tahun) terhadap suhu

\section{KESIMPULAN}

Dalam ekstrak daun pandan terkandung senyawa-senyawa metabolit sekunder flavonoid, steroid, alkaloid, antrakuinon, dan tannin, sehingga ekstrak daun pandan berpotensi sebagai inhibitor alami dalam menghambat proses korosi suatu logam.

Semakin tinggi konsentrasi ekstrak daun pandan, semakin tinggi efisiensi inhibisi yang ditunjukkan. Sementara semakin besar suhu, efisiensi inhibisi arginin pada korosi baja SS-304 semakin menurun. Efisiensi inhibisi yang paling tinggi pada penelitian ini diperoleh pada konsentrasi $0.8 \%$, yaitu sebesar $89,90 \%$. Efisiensi inhibisi yang semakin tinggi menunjukkan laju korosi yang semakin menurun.

\section{DAFTAR PUSTAKA}

Adfa M., 2005. Survey Etnobotani, Studi senyawa flavanoid dan uji brine shrimp beberapa tumbuhan obat 
tradisional suku Serawai di provinsi Bengkulu. Jurnal Gradien, 1(1): 4350.

Agustiningsih, Wildan, A., dan Mindaningsih, 2010. Optimasi cairan penyari pada pembuatan ekstrak daun pandan wangi (Pandanus amaryllifous Roxb) secara maserasi terhadap kadar fenolik dan flavonoid total. Momentum, 6(2): 36-41.

Amin, M.A. and Ibrahim, M.M., 2011. Corrosion and corrosion control of mild steel in concentrated $\mathrm{H}_{2} \mathrm{SO}_{4}$ solutions by a newly synthesized glycine derivative. Corrosion Science, 53(3): 873-885.

Bentiss, F., Trisnel, M., and Lagrence, M., 2000. The substituted 1,3,4oxadiazoles: a new class of corrosion inhibitors of mild steel in acidic media. Corrosion Science, 42(1) : 127146.

Caliskan, N., and Akbas, E., 2011. The Inhibition effect of some pyrimidine derivates on austenitic stainless steel in acidic media. Materials Chemistry and Physics, 126(3): 983-988.

Damayanti, A., dan Fitriana, E. A., 2012. Pemungutan minyak atsiri mawar (rose oil) dengan metode maserasi. Jurnal Bahan Alam Terbarukan, 1(2): 1-8, ISSN: 2303-0623.

Gusti, D. R., Farid, F., dan Lestari I. Ekstrak kulit Kayu Akasia sebagai Inhibitor Pada Laju Korosi Baja Lunak Dalam media Asam Sulfat, Prosiding Semirata, 2013, FMIPA Universitas Lampung, Lampung.

Harbone, J. B. (1978). Metode fitokimia: Penuntun Cara Modern Menganalisis Tumbuhan. (terjemahan Padmawinata, K, Soediro, I). Terbitan kedua. ITB, Bandung.

Irianty, R. S., Khairat, 2013. Ekstrak daun papaya sebagai inhibitor korosi baja AISI 4140 dalam medium air laut. Jurnal Teknobiologi, IV(2): 77-82, ISSN: 2087-5428.
Khopkar, S. M. (2003). Konsep Dasar Kimia (terjemahan Saptohardjo A). Universitas Indonesia, Jakarta.

Prameswari, O. M., dan Widjanarko, S. B., 2014. Uji Efek Esktrak Air Daun Pandan Wangi terhadap Penurunan Kadar Glukosa Darah dan Histopatologi Tikus Diabetes Melitus. Jurnal Pangan dan Agroindustri, 2(2): 16-27.

Scendo, M., 2007. The effect of purine on the corrosion of copper in choride solution. Corrosion Science, 49(2): 373-390.

Shreir, L. L., Jarman, R. A., and Burstein, G. T. (1994). Corrosion, Corrosion Control. Volume 2, Butterworth Heinemann, London.

Spinelli, A., and De Souza F. S., 2009. Caffeic acid as a green corrosion inhibitor for mild steel. Corrosion Science 51(3): 642 - 649 .

Soltani, N., Tavakkoli, N., Khayatkashani, M., and Jalali, M. R., 2012. Green approach to corrosion inhibition of 304 stainless steel in hydrochloric acid solution by the extract of salvia officinalis leaves, Corrosion Science, 62, 122-135.

Vimala, J. R., Rose, A. L., and Raja, S., 2012. A study on the phytochemical analysis and corrosion inhibition on mild steel by annona muricata.L leaves extract in 1hydrochloric acid, Der Chemica Sinica, 3(3): 582-588, ISSN: 0976-8505.

Wahyuningsih, A., Sunarya, Y., dan Aisyah, S., 2010. Metenamina sebagai Inhibitor Korosi Baja Karbon dalam Lingkungan Sesuai Kondisi Pertambangan Minyak Bumi. Jurnal Sains dan Teknologi Kimia, 1(1): 1729, ISSN: 2087-7412. 